\title{
Transcriptome analysis of hen preadipocytes treated with an adipogenic cocktail (DMIOA) with or without 20(S)-hydroxylcholesterol
}

Alemu Regassa ${ }^{1}$ and Woo Kyun Kim ${ }^{1,2^{*}}$

\begin{abstract}
Background: 20(S)-hydroxycholesterol (20(S)) potentially reduces adipogenesis in mammalian cells. The role of this oxysterol and molecular mechanisms underlying the adipogenesis of preadipocytes from laying hens have not been investigated. This study was conducted to 1. Analyze genes differentially expressed between preadipocytes treated with an adipogenic cocktail (DMIOA) containing $500 \mathrm{nM}$ dexamethasone, $0.5 \mathrm{mM}$ 3-isobutyl-1-methylxanthine, $20 \mu \mathrm{g} / \mathrm{mL}$ insulin and $300 \mu \mathrm{M}$ oleic acid (OA) and control cells and 2. Analyze genes differentially expressed between preadipocytes treated with DMIOA and those treated with DMIOA + 20(S) using Affymetrix GeneChip ${ }^{\oplus}$ Chicken Genome Arrays.

Results: In experiment one, where we compared the gene expression profile of non-treated (control) cells with those treated with DMIOA, out of 1,221 differentially expressed genes, 755 were over-expressed in control cells, and 466 were over-expressed in cells treated with DMIOA. In experiment two, where we compared the gene expression profile of DMIOA treated cells with those treated with DMIOA+20(S), out of 212 differentially expressed genes, 90 were overexpressed in cells treated with DMIOA, and 122 were over-expressed in those treated with DMIOA+20(S).

Genes over-expressed in control cells compared to those treated with DMIOA include those involved in cell-to-cell signaling and interaction (IL6, CNN2, ITGB3), cellular assembly and organization (BMP6, IGF1, ACTB), and cell cycle (CD4, 9, 38). Genes over-expressed in DMIOA compared to control cells include those involved in cellular development (ADAM22, ADAMTS9, FIGF), lipid metabolism (FABP3, 4 and 5), and molecular transport (MAP3K8, PDK4, AGTR1). Genes over-expressed in cells treated with DMIOA compared with those treated with $\mathrm{DMIOA}+20(\mathrm{~S})$ include those involved in lipid metabolism (ENPP2, DHCR7, DHCR24), molecular transport (FADS2, SLC6A2, CD36), and vitamin and mineral metabolism (BCMO1, AACS, AR). Genes over-expressed in cells treated with DMIOA+20(S) compared with those treated with DMIOA include those involved in cellular growth and proliferation (CD44, CDK6, IL1B), cellular development (ADORA2B, ATP6VOD2, TNFAIP3), and cell-to-cell signaling and interaction (VCAM1, SPON2, VLDLR).
\end{abstract}

Conclusion: We identified important adipogenic regulators and key pathways that would help to understand the molecular mechanism of the in vitro adipogenesis in laying hens and demonstrated that 20(S) is capable of suppressing DMIOA-induced adipogenesis.

Keywords: Adipogenesis, Hen preadipocytes, 20(S)-hydroxycholestrol, Microarray

\footnotetext{
* Correspondence: wkkim@uga.edu

'Department of Animal Science, University of Manitoba, Winnipeg, Manitoba, Canada

${ }^{2}$ Department of Poultry Science, University of Georgia, 303 Poultry Science Building, Athens, GA 30602, U.S.A
}

\section{Biomed Central}

(c) 2015 Regassa and Kim; licensee BioMed Central. This is an Open Access article distributed under the terms of the Creative Commons Attribution License (http://creativecommons.org/licenses/by/4.0), which permits unrestricted use, distribution, and reproduction in any medium, provided the original work is properly credited. The Creative Commons Public Domain Dedication waiver (http://creativecommons.org/publicdomain/zero/1.0/) applies to the data made available in this article, unless otherwise stated. 


\section{Background}

Adipogenesis is the process in which preadipocytes become adipocytes, and it is one of the most intensively studied models of cellular differentiation. Adipocytes play vital roles in energy homeostasis and possess the largest energy reserve in the body of animals [1]. The increase in adipose tissue mass results from multiplication of fat cells through a process called adipogenesis, where undifferentiated precursor cells (preadipocytes) differentiate into fat cells [2].

A number of key transcriptional activities are involved in the process of adipogenesis in mammals [3-5]. The critical step in these events is the activation of the transcription factor CCATT enhancer-binding protein beta $(\mathrm{C} / \mathrm{EBP} \beta)$ by mitogen activated protein kinase (MAPK) and glycogen synthase kinase-3 beta (GSK3 $\beta$ ) [6]. The activated $C / E B P \beta$ then triggers transcription of peroxisome proliferator-activated receptor gamma 2 (PPAR 2 ) and CCATT enhancer-binding protein alpha $(\mathrm{C} / \mathrm{EBP} \alpha)$, which in turn additively activate the expression of genes responsible for the development of mature adipocytes [3].

Oleic acid (OA) has been implicated as a good source of exogenous fatty acids essential for adipocyte differentiation and plays an important role in the development of adipose tissue in chickens [7]. Preadipocytes isolated from broilers (meat-type chicken) treated with $300 \mu \mathrm{M}$ OA showed marked increase in the expression of genes responsible for adipocyte formation [7].

An adipogenic cocktail containing $500 \mathrm{nM}$ dexamethasone, $0.5 \mathrm{mM}$ 3-isobutyl-1-methylxanthine, and $20 \mu \mathrm{g} /$ $\mathrm{mL}$ insulin (DMI) has been commonly used to induce adipogenesis in various animal models $[3,4,8,9]$. However, DMI treatment without OA does not induce key adipogenic transcription factors and adipogenesis in chicken preadipocytes $[7,10]$ explaining the unique characteristic of chicken fat cell adipogenesis in vitro.

Oxysterols are bioactive molecules involved in numerous biological processes including cholesterol efflux [11], lipoprotein and calcium metabolisms [12], cell differentiation [13], and apoptosis [14] and are potential candidates for changing the fate of mesenchymal stem cell (MSC) differentiation [15]. While inhibiting adipogenic differentiation, specific oxysterols namely, 20(S)-hydroxycholesterol $(20(S))$ in combination with $22(\mathrm{~S})$ - or 22 (R)-hydroxycholesterol, induce osteoblastic differentiation of mouse pluripotent mesenchymal cells [16] through protein kinase $\mathrm{C}(\mathrm{PKC})$ and protein kinase $\mathrm{A}$ (PKA) dependent mechanisms [17]. These proosteogenic and anti-adipogenic effects of specific oxysterols are marked by the early and late markers of osteogenic differentiation such as increased alkaline phosphatase (ALP) activity, osteocalcin (OCN) mRNA expression and mineralization, and reduction in markers of adipogenic differentiation including lipoprotein lipase (LPL) and fatty acid binding protein 4 (FABP4) mRNA expression and adipocyte formation [16]. Furthermore, 20(S) inhibits PPAR 2 expression and adipogenic differentiation of mouse bone marrow stromal cells through a hedgehog (Hh)-dependent mechanism [15]. Similarly, treatment of mouse M2-10B4 MSC with Oxy34 or Oxy49 induces the expression of osteogenic differentiation markers, Runx2, Osterix (OSX), ALP, bone sialoprotein (BSP), and OCN as well as ALP enzymatic activity and robust mineralization [18]. On the other hand, treatment of these cells with the oxysterols inhibits the expression of adipogenic genes such as (PPARy2), LPL, and FABP4, and adipocyte formation induced by PPAR $\gamma 2$ activator, troglitazone [18]. Additionally, treatment of human adipose-derived stem cells with 7-Ketocholesterol and 5,6-S oxysterols has been reported to detrimentally modulate mitochondrial activity and adipogenic differentiation of adipose precursor cells [19]. However, no studies have been conducted to elucidate global gene regulation of adipogenesis and antiadipogenic mechanisms of oxysterols in chicken preadipocytes. Here, we hypothesized that treatment of hen preadipocytes with $20(\mathrm{~S})$ reduces DMIOA-induced adipogenesis by affecting various pathways and gene networks involving key adipogeneic transcription factors. This study was conducted to identify genes differentially expressed between preadipocytes treated with DMIOA and control cells and genes differentially expressed between preadipocytes treated with DMIOA alone and those treated with a combination of DMIOA and 20(S).

\section{Methods}

\section{Care of experimental birds}

All experimental procedures were reviewed and approved by the University of Manitoba Animal Care Protocol Management and Review Committee, and birds were handled in accordance with guidelines described by the Canadian Council on Animal Care (CCAC, 1993).

\section{Cell culture}

Abdominal adipose tissues weighing approximately $4 \mathrm{gm}$ were collected from three 19-wk old laying hens (Gallas gallus, Lohman strain) by sterile dissection as described in [7]. We selected 19-wk old laying hens because hens start laying eggs, maximize their fat accumulation in the body and have dramatic metabolic changes related to lipid metabolism at this age. The adipose tissues were minced into fine sections with scissors and incubated in $10 \mathrm{~mL}$ Dulbecco's Modified Eagle's Medium (DMEM) digestion buffer containing $0.1 \%$ collagenase, $2.8 \mathrm{mM}$ glucose, and $4 \%$ bovine serum albumin (BSA) for $45 \mathrm{~min}$ at $37^{\circ} \mathrm{C}$ in a shaking water bath. After the incubation, the contents were filtered using 100 and $40 \mu \mathrm{m}$ Nylon 
meshes (Fisher Scientific, China), and the filtrates were centrifuged at $1,800 \mathrm{rpm}$ for $10 \mathrm{~min}$ to separate floating adipocytes from pellets of preadipocytes. The supernatant was discarded, and cell pellets were resuspended in $10 \mathrm{~mL} 1 \mathrm{X}$ DMEM containing 10\% fetal bovine serum (FBS), $100 \mathrm{U} / \mathrm{mL}$ penicillin, $100 \mu \mathrm{g} / \mathrm{mL}$ streptomycin and L-glutamate (Mediatech, Inc., Manassas, VA). Preadipocytes were then seeded in $100 \mathrm{~mm}$ Petri dishes (MG Scientific, Wisconsin, USA) and cultured in an incubator with $95 \%$ air and $5 \% \mathrm{CO}_{2}$ at $37^{\circ} \mathrm{C}$. Cells were checked for viability every day, and the media were changed every three days until the cells were confluent. At confluence, the cells were washed twice in $5 \mathrm{~mL}$ phosphate buffered saline (PBS) and incubated in $3 \mathrm{~mL}$ of $1 \mathrm{X}$ TrisEDTA (TE) buffer for $2 \mathrm{~min}$ at $37^{\circ} \mathrm{C}$. The cells were washed several times in seven $\mathrm{mL}$ of $1 \mathrm{X}$ DMEM containing 10\% FBS to detach adhering cells. The contents were centrifuged at $1,800 \mathrm{rpm}$ for $5 \mathrm{~min}$, the supernatant was discarded, and cell pellets were re-suspended in
$5 \mathrm{~mL}$ of $1 \mathrm{X}$ DMEM containing 10\% FBS. Then, the cells were plated in six-well plates at 20,000 cells $/ \mathrm{cm}^{2}$ and incubated until they reached confluence. The cells became confluent after two days of incubation.

\section{Incubation of cells with an adipogenic cocktail and 20(S)-} hydroxycholesterol

After confluence, the cells were treated with 1) an adipogenic cocktail containing $500 \mathrm{nM}$ dexamethasone, $0.5 \mathrm{mM}$ 3-isobutyl-1-methylxanthine, $20 \mu \mathrm{g} / \mathrm{mL}$ insulin and $300 \mu \mathrm{M}$ OA (DMIOA), and 2) DMIOA + $5 \mu \mathrm{M} 20$ (S) with three biological replicates per treatment for $96 \mathrm{hr}$. Cells were incubated for $96 \mathrm{hr}$ because our recent observation showed that sufficient lipid droplets were formed by DMIOA treatment and 20(S) started inhibiting adipogenic gene (FABP4) at this time point (Figures 1 and 2). Non-treated cells were cultured in 1X DMEM containing $10 \%$ FBS without an adipogenic cocktail for comparison purpose. The media was removed from the
(A)
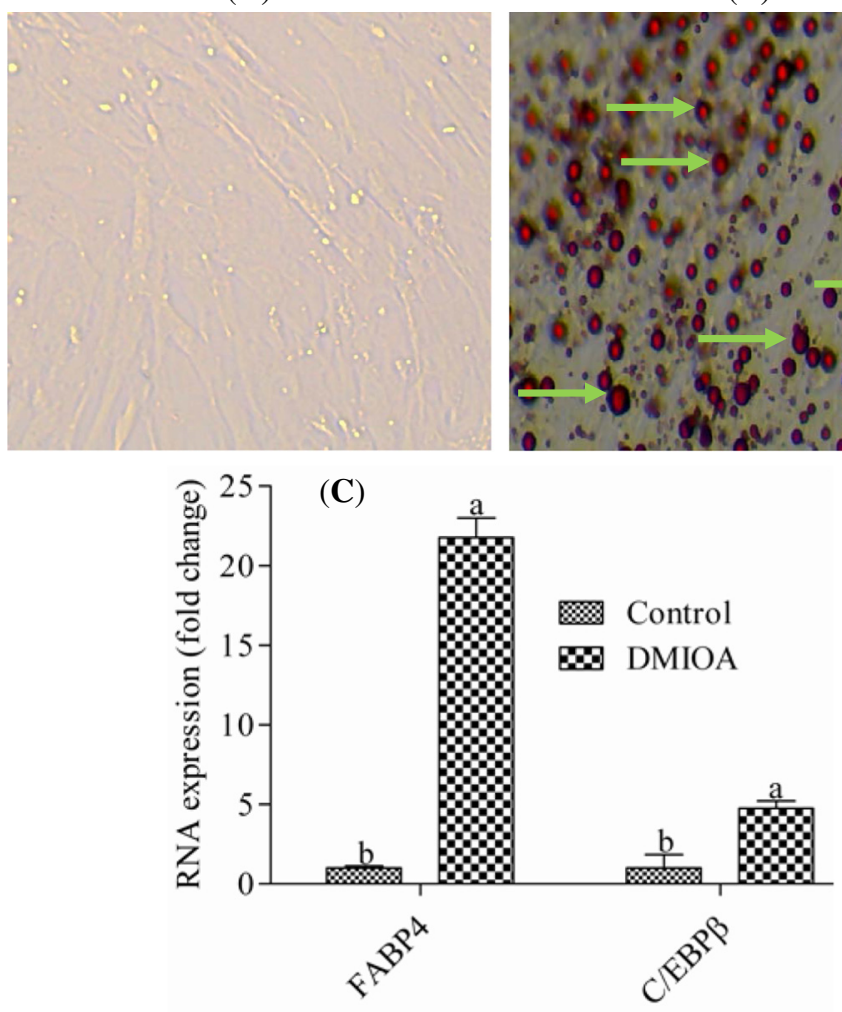

Gene name

Control

DMIOA
(B)

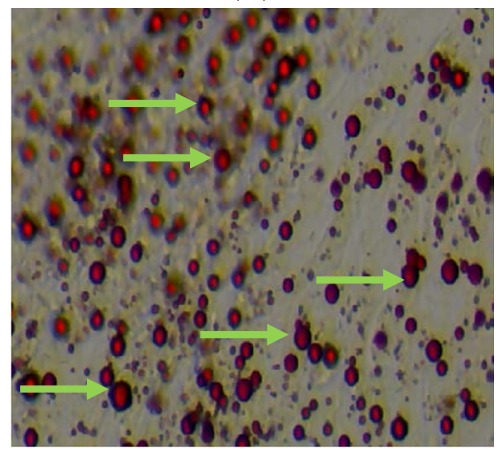
Figure 1 Representative images of non-treated preadipocytes (1A), preadipocytes treated with DMIOA (1B), showing remarkable lipid
accumulation in preadipocytes treated with DMIOA and relative expressions of FABP4 and C/EBPB in control and DMIOA treated cells (1C). Preadipocytes were cultured in Dulbecco's modified eagle's medium (DMEM) containing 10\% fetal bovine serum (FBS) for 96 hr. Images were taken using an EVOS ${ }^{\circledR} \mathrm{xl}$ core cell culture microscope (Advanced Microscopy Group, Seattle, USA) at 20X magnification. Green arrows indicate lipid droplets stained with Oil red $\mathrm{O}$ stain whereas there is no lipid formation in non-treated cells. C: Fold change expression of FABP4 and $\mathrm{C} / \mathrm{EBP} \beta$ in preadipocytes treated with an adipogenic cocktail (DMIOA) compared with non-treated cells. Preadipocytes were cultured in Dulbecco's modified eagle's medium containing 10\% Fetal Bovine Serum for 96 hr. Bars with different letters are significantly different $(P<0.05)$. The bars represent Mean $\pm S D(N=3)$. 


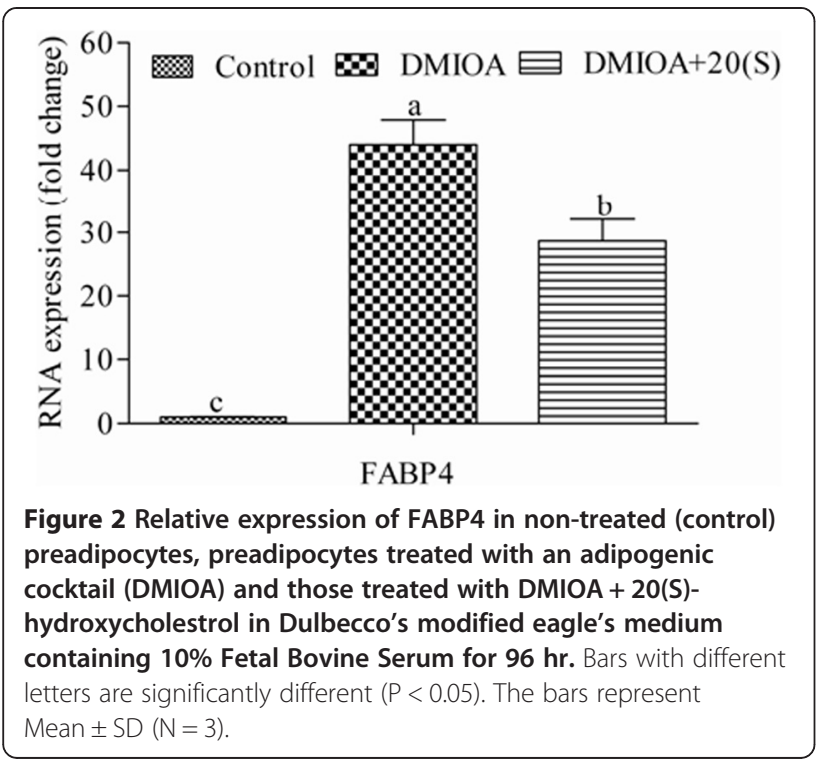

cells using a vacuum aspirator, and the cells were homogenized in one $\mathrm{mL}$ of TRIzol (Invitrogen, Canada) for RNA isolation.

\section{Oil red $\mathrm{O}$ staining of preadipocytes}

In order to examine the effect of an adipogenic cocktail on adipogenesis and accumulation of lipid droplets, preadipocytes isolated from 19 -wk old laying hens were treated with DMIOA containing $500 \mathrm{nM}$ dexamethasone, $0.5 \mathrm{mM}$ 3-isobutyl-1-methylxanthine, $20 \mu \mathrm{g} / \mathrm{mL}$ insulin and $300 \mu \mathrm{M}$ OA for $96 \mathrm{hr}$. Then, non-treated control cells and cells treated with DMIOA were stained with Oil Red O according to supplier's protocol [20].

\section{RNA isolation and array processing}

Total RNA was extracted from cells representing three biological replicates per treatment using TRIzol (Invitrogen, Canada) according to the manufacturer's protocol. RNA integrity and yield of each sample were determined using an Experion $^{\mathrm{TM}}$ automated electrophoresis system (Bio-Rad laboratories Inc, USA) and a NanoDrop 2000 (Thermo Scientific, Canada), respectively. Initial total RNA concentrations across all samples were adjusted to $500 \mathrm{ng}$, and this amount of total RNA was used for the two round cDNA synthesis and subsequent in vitro-transcription according to the one-cycle eukaryotic target labeling assay (Affymetrix GeneChip ${ }^{\oplus}$ 3' IVT express Kit). Fifteen $\mu$ g of biotin-labeled and amplified RNA (aRNA) of each group were hybridized with Affymetrix GeneChip ${ }^{\circ}$ Chicken Genome Arrays for $16 \mathrm{hr}$ at $45^{\circ} \mathrm{C}$. Post-hybridization staining and washing were performed according to manufacturer's protocols using a Fluidics Station 450 instrument (Affymetrix, USA).
Image capturing, quantification and data analysis

Array slides were scanned with a GeneChip ${ }^{\mathrm{Tm}} 3000$ laser confocal slide scanner (Affymetrix, USA), and the images were quantified using Affymetrix GeneChip Command Console Software (Affymetrix, USA). Probe level data were imported into FlexArray software [21]. The raw data were background corrected, normalized, and summarized using Guanine-Cytosine Robust Multichip Average (GCRMA) function as described in [22]. The background corrected and normalized data were then filtered by applying a false discovery rate of $<5 \%$. The filtered genes were annotated using a chicken annotation file (Chicken. na32.annot, Affymetrix, USA). Genes differentially expressed (1) between non-treated (control) cells and cells treated with DMIOA and (2) between cells treated with DMIOA alone and a combination of DMIOA and 20(S) were identified using a t-test at a fold change of $\geq 2$ and probability $(\mathrm{P}<0.05)$. The raw data from all arrays in this study are available online at http://www.ncbi.nlm.nih.gov/geo/ with GEO accession number GSE50880.

Lists of genes over-expressed in either group were uploaded into Ingenuity Pathways Analysis [23] to identify the most significantly affected gene networks and cellular functions, relationships between the genes of interest, and pathways involved.

Validation of microarray data using quantitative real-time reverse transcription polymerase chain reaction (qRT-PCR) The same RNA samples that were used for array hybridization were used for cDNA synthesis. First strand cDNA was synthesized using a high capacity reverse transcription kit according to the supplier's protocol (Applied Biosystems, Canada). Pairs of primers for each gene were designed from the mRNA sequence of target gene using the National Centre for Biotechnology Information (NCBI). Quantitative real-time RT-PCR was performed in duplicate reactions including nuclease free water, the forward and reverse primers of each gene, template cDNA and SYBR Green using a CFX Connect ${ }^{\mathrm{T}}$ Real-Time PCR Detection System (Life Science Research, Bio-Rad, Canada). Data were generated using a $\Delta \Delta \mathrm{Ct}$ method by normalizing the expression of the target genes to a housekeeping gene (GAPDH), and the values were reported as fold changes of the expression of the target genes in DMIOA treated cells compared with the control group and the expression of target genes in DMIOA $+20(\mathrm{~S})$ treated cells compared with DMIOA group. Gene expression and correlation between microarray and qRT-PCR data were analysed using t-test and correlation procedures of SAS software [24], respectively. Means were declared significant at $\mathrm{P}<0.05$. Pairs of primers used for $q R T-P C R$ assay and their sequences are presented in Table 1. 
Table 1 List of primers used for quantitative real-time polymerase chain reaction

\begin{tabular}{|c|c|c|c|c|}
\hline Name & Forward & Reverse & Product length (base pair) & Annealing temperature $\left({ }^{\circ} \mathrm{C}\right)$ \\
\hline FABP4 & GAGTTTGATGAGACCACAGCAGA & ATAACAGTCTCTTTGCCATCCCA & 106 & 57 \\
\hline IGFBP7 & TCCATCGTGACCCCTCCTAA & GAGAGATCAGTACCCAGCCG & 228 & 55 \\
\hline VEGFC & AAGTGTGTGTGGATGTGGGG & TGACAGTTACGGGTTTGGGG & 201 & 55 \\
\hline CD44 & CGCTGTGCGGAGATACAGAA & CCTATGGCTCTTCCTGGCTG & 199 & 55 \\
\hline MMP1 & GCAGTCTCCTCTGCTITCCC & GTCACGGTCAGGTTTCCCAG & 209 & 58 \\
\hline STARD4 & GGGACAGCACAAGCCCTAAT & GCCTAGCTTGACTGGGTTCA & 219 & 54 \\
\hline INSIG1 & GCATGGTGCCAGTGTGAAAG & TCCAGAGAACAGCCATACGC & 222 & 54 \\
\hline GAPDH & GCTAAGGCTGTGGGGAAAGT & TCAGCAGCAGCCTTCACTAC & 116 & 55 \\
\hline TGM4 & TGGATGTCCTCTGACTCCGT & CAGTAGACCTTGTCGGCGTT & 238 & 54 \\
\hline CCL4 & CTCATGGCAGGTGCTGTTTG & ССТСССТTAAATGCCСТCCC & 207 & 55 \\
\hline TNFAIP3 & CAGAAAAGAGGCCTGCTCCA & CCTTCAGTTTCTCGGGTGCT & 202 & 54 \\
\hline GSTA3 & GCCAAAGGAAACCACGCCTA & GTTCATCCAGTGTACCGCCT & 218 & 55 \\
\hline APOA1 & CTCGCTGTGCTCTTCCTGAC & GTCAGCCAGCTTCAGGTCAA & 191 & 55 \\
\hline KLF2 & CTTACCCGCCACTACCGAAA & TTGTCCGGCTCTGTCCTAAG & 123 & 58 \\
\hline HAS2 & CACTGGGAGAAGCGTGGAAT & GCACTGTACGCAGCCAAAAT & 203 & 56 \\
\hline
\end{tabular}

\section{Results}

The effect of DMIOA on the adipogenesis and expression of key adipogenic transcripts

The results of our pre-experiment investigation indicated that, preadipocytes treated with DMIOA had remarkably higher lipid accumulation (Figure 1B) and significantly higher $(\mathrm{P}<0.05)$ expression of key adipogenic transcripts such as FABP4 and C/EBP $\beta$ compared with non-treated cells (Figure 1C).

\section{The effect of 20(S)-hydroxycholesterol (20(S)) on the expression of FABP4}

In order to study the effect of oxysterol on the expression of adipogenic transcripts, preadipocytes isolated from 19-wk laying hens were treated with DMIOA with or without $20(\mathrm{~S})$. The result indicated that DMIOA treatment significantly increased $(\mathrm{P} \leq 0.05)$ the expression of one of the key adipogenic transcript (FABP4) compared to control cells, whereas DMIOA + 20(S) treatment significantly reduced DMIOA-induced FABP4. expression (Figure 2).

\section{Transcriptome profiles of chicken preadipocytes treated} with DMIOA relative to non-treated (control) cells

Global transcriptome expression analyses of preadipocytes treated with DMIOA and non-treated cells showed that of 1,221 differentially expressed genes, 755 were over-expressed in non-treated cells (Additional file 1), and 466 were over-expressed in cells treated with DMIOA (Additional file 2). Hierarchical clustering of all genes differentially expressed between control cells and cells treated with DMIOA and the top 20 genes differentially expressed between the two groups are indicated in Additional files 3 and 4, respectively.

Genes over-expressed in control cells compared to those treated with DMIOA include those involved in cell-to-cell signaling and interaction such as interleukin 6 (IL6), calponin 2 (CNN2), and integrin beta 3 (ITGB3), cell morphology such as ATPase, $\mathrm{Ca}^{++}$transporting, plasma membrane 2 (ATP2B2), insulin like growth factor 3 (IGFB3), and inhibin beta A (INHBA), cellular assembly and organization such as bone morphogenetic protein 6 (BMP6), insulin like growth factor 1 (IGF1), beta actin (ACTB), and adenylyl cyclase-associated Protein 2 (CAP2), cellular function and maintenance such as integrin alpha 4 (ITGA4), integrin beta 2 (ITGB2), and growth and differentiation factor 9 (GDF9), and cell cycle such as CD4, 9 and 38 molecules (CD4, CD9, CD38), and cyclin-dependent kinase inhibitor 2B (CDKN2B). Genes over-expressed in DMIOA compared to control cells include those involved in cellular development such as ADAM metallopeptidase domain 22 (ADAM22), ADAM metallopeptidase with thrombospondin type 1 motif, 9 (ADAMTS9), c-fos induced growth factor (FIGF), and matrix metallopeptidase 1 (MMP1), lipid metabolism such as fatty acid binding protein 3, 4, and 5 (FABP3, 4 and 5), and apolipoprotein 1 (APOA1), molecular transport such as mitogene activated protein 3 kinase 8 (MAP3K8), pyruvate dehydrogenase kinase, isozyme 4 (PDK4), solute carrier organic anion transporter family, member 2B1 (SLCO2B1), and nicotinamide phosphoribosyltransferase (NAMPT), and small molecule biochemistry such as angiotensin II receptor, type 1, 2 and 3 (ATGR1, ATGR2, ATGR3), and glutaminefructose-6-phosphate transaminase 2 (GFPT2) (Figure 3). 
Functional grouping (canonical pathways) of genes that were over-expressed in control preadipocytes relative to those treated with DMIOA is presented in Figure 4. Several key gene networks were also affected by DMIOA treatment relative to control cells. An example of a gene network (lipid metabolism) showing the relationships between molecules over-expressed in preadipocytes treated with DMIOA compared with control cells is presented Figure 5.

\section{Transcriptome profile of chicken preadipocytes treated with DMIOA alone and a combination of DMIOA and 20} (S)

The gene expression data indicated that of 212 differentially expressed genes, 90 were over-expressed in cells treated with DMIOA alone (Additional file 5), and 122 were over-expressed in those treated with a combination of DMIOA and 20(S) (Additional file 6). Hierarchical clustering of all genes differentially expressed between cells treated with DMIOA and those treated with $\mathrm{DMIOA}+20(\mathrm{~S})$ and the top 20 genes differentially

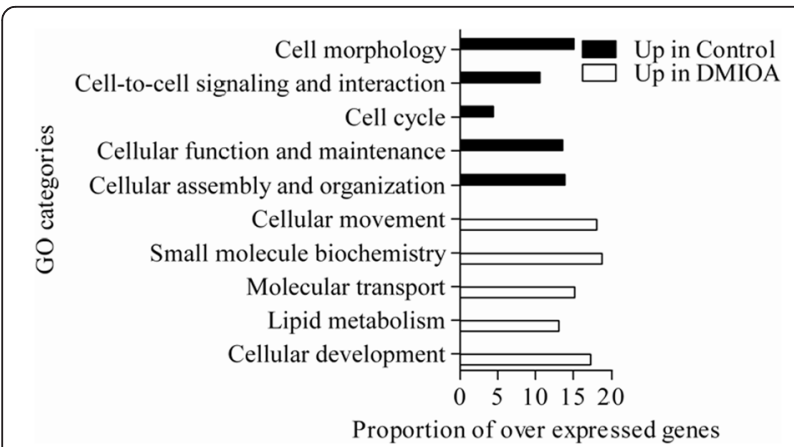

Figure 3 The top significantly changed gene ontology (GO) terms (molecular and cellular functions) with the proportion of genes involved among these over-expressed in non-treated preadipocytes (black bars) and those treated with an adipogenic cocktail (DMIOA) (white bars) in Dulbecco's modified eagle's medium containing $10 \%$ Fetal Bovine Serum for $96 \mathrm{hr}$. Lists of genes over-expressed in a given treatment group relative to the other were imported into IPA and the number of genes that were associated with a given GO term in the IPA database was determined at $P<0.0001$. The $P$-value, calculated using the right-tailed Fisher Exact Test, is a measure of the likelihood that the association between the number of focus genes in the data set and a given GO term is due to random chance. The smaller the P-value is the less likely that the association is random, and the more significant the association is. The $\mathrm{p}$-value for a given $\mathrm{GO}$ term was calculated by considering the number of focus genes that participate in a given $\mathrm{GO}$ term and the total number of genes that are known to be associated with that GO term in the Ingenuity Knowledge Base. Then, the proportion of genes in a given $\mathrm{GO}$ term was calculated by dividing the number of genes determined by IPA that are associated with a given GO term in the Ingenuity ${ }^{\circledR}$ Knowledge Base by the total number of genes

over-expressed in one treatment group relative to the other multiplied by 100 . expressed between the two groups are indicated in Additional files 7 and 8, respectively.

Genes over-expressed in cells treated with DMIOA alone compared with those treated with DMIOA + 20(S) include those involved in lipid metabolism such as ectonucleotide pyrophosphatase/phosphodiesterase 2 (ENPP 2), 7-dehydrocholesterol reductase (DHCR7), 24-dehyd rocholesterol reductase (DHCR24), 3-hydroxy-3-methylglutaryl-CoA reductase (HMGCR), farnesyl-diphosphate farnesyltransferase 1 (FDFT1), and farnesyl diphosphate synthase (FDPS), small molecule biochemistry such as solute carrier family 16 member 10 (SLC16A10), fibroblast growth factor 7 (FGF7), StAR-related lipid transfer (START) domain containing 4 (STARD4), and insulin induced gene 1 (INSIG1), molecular transport such as fatty acid desaturase 2 (FADS2), solute carrier family 6 member 2 (SLC6A2), glypican 1 (GPC1), and CD molecule 36 (CD36), and vitamin and mineral metabolism such as beta-carotene 15,15' -monooxygenase (BCMO1), acetoacetyl-CoA synthetase (AACS), androgen receptor (AR), and hydroxysteroid (17-beta) dehydrogenase 7 (HSD17B7). Genes over-expressed in cells treated with $\mathrm{DMIOA}+20(\mathrm{~S})$ compared with those treated with DMIOA alone include those involved in cellular growth and proliferation such as CD molecule 44 (CD44), cyclin dependent kinase 6 (CDK6), interleukin 1 beta (IL1B), interleukin 6, and 8 (IL6, and 8), cellular development such as adenosine A2b receptor (ADORA2B), ATP synthase (ATP6), tumor necrosis alpha induced protein 3 (TNFAIP3), and tumor necrosis factor (ligand) superfamily, member 15 (TNFSF15), cellular movement such as chemokine (C-C motif) ligand 20 (CCL20), cholecystokinin (CCK), and vasoactive intestinal polypeptid (VIP), and cell-to-cell signaling and interaction such as vascular cell adhesion molecule 1 (VCAM1), spondin 2, extracellular matrix protein (SPON2), very low density lipoprotein receptor (VLDLR), and cytoplasmic polyadenylation element binding protein 1 (CPEB1). The gene ontology (GO) terms (cellular and molecular functions) and functional groups (canonical pathways) of genes differentially expressed between cells treated with DMIOA alone and those treated with DMIOA $+20(\mathrm{~S})$ are shown in Figures 6, 7 and 8, respectively. The results of functional (pathway) analysis indicated that the majority of genes over-expressed in cells treated with DMIOA relative to those treated with DMIOA $+20(\mathrm{~S})$ are involved in cholesterol biosynthesis I, II and III pathways (Figure 7). On the other hand, the majority of genes over-expressed in cells treated with DMIOA $+20(\mathrm{~S})$ are involved in hepatic cholestasis, IL-6, IL-10, and LPS (IL-1) mediated inhibition of RXR function (Figure 8).

Key gene networks showing the relationships between molecules over-expressed in cells treated with DMIOA and those treated with $\mathrm{DMIOA}+20(\mathrm{~S})$ relative to each 


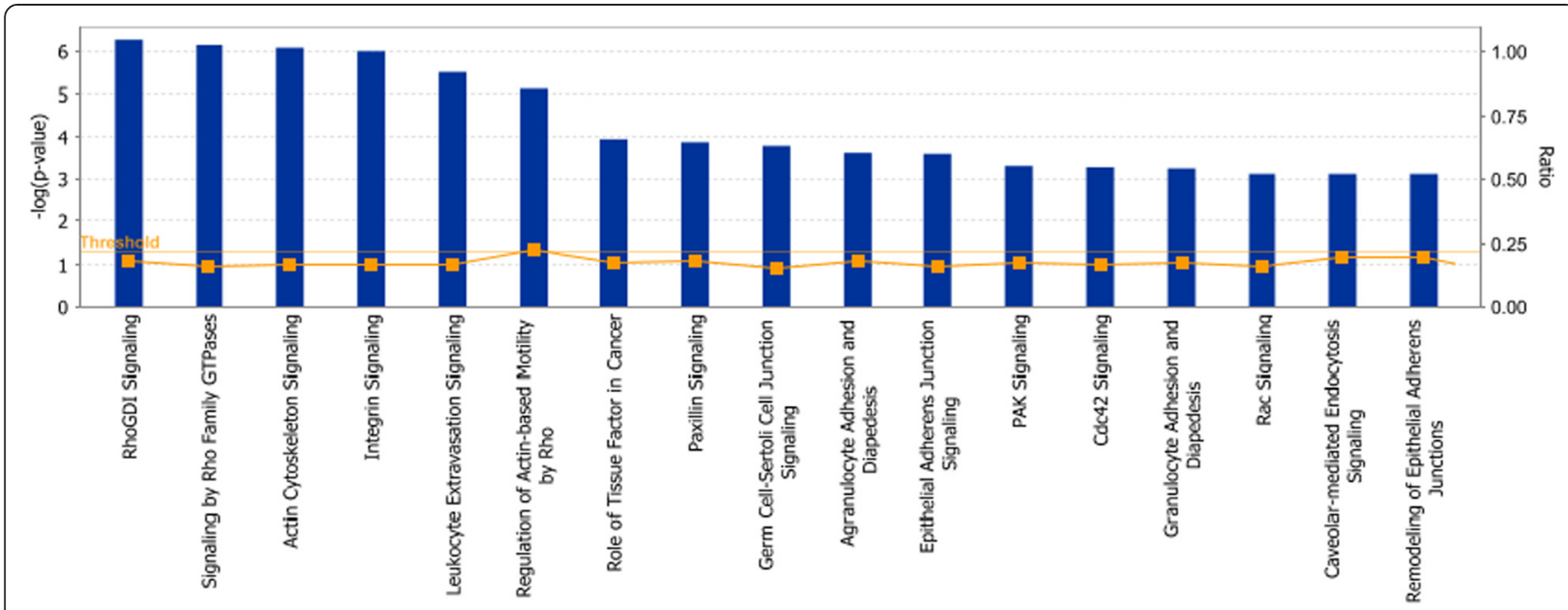

Figure 4 Functional grouping of genes that were over-expressed in non-treated preadipocytes relative to those treated with an adipogenic cocktail (DMIOA) showing the most significant functional groups, with $\mathbf{P}$ value $\leq \mathbf{0 . 0 5}$. The bars represent the $P$-value in a logarithmic scale for each functional group.

other are presented in Figures 9 and 10. One of the gene networks that were affected by DMIOA treatment is a lipid metabolism gene network including signaling molecules such as INSIG1, STARD4, SQLE and others (Figure 9), whereas the network affected by DMIOA + $20(S)$ includes genes that are involved in interleukin signaling pathways such as IL-1, IL-1R, IL1RL2, TNFAIP3, CCL20 (Figure 10).

Validation of microarray data using quantitative real-time reverse transcription polymerase chain reaction (qRT-PCR) In order to validate the microarray data, we selected representative genes and analyzed their expression using qRT-PCR. Except for one gene, HAS2, the results were consistent with the microarray data. Additionally, correlation analysis of the microarray and qRT-PCR data showed a strong positive correlation ( $\mathrm{r}=0.989$; $\mathrm{P}<0.001$ ) between the two data sets. Microarray and RT-PCR fold differences are shown in Table 2.

\section{Discussion}

\section{The role of microarray in chicken transcriptomics}

The use of microarray in chicken transcriptome analysis is recently increasing. For instance, microarray-based gene expression studies were conducted on adipose tissues collected from 7- [25] and 9- [26] wk old broiler chickens to identify genes differentially expressed between fat and lean lines. Systematic identification of candidate genes and new pathways related to intramuscular fat deposition in chicken breast tissues has also been made using gene expression profiles of two distinct breeds [27] showing the wide use of microarray in gene expression studies and identification of important pathways and biological processes in chicken.
The effect of an adipogenic cocktail (DMIOA) on adipogenesis and expression of adipogenic genes In the present study, we detected numerous genes overexpressed in preadipocytes treated with DMIOA compared with non-treated cells including ENPP2, RLN3, ADAMTS9, HPGD, LCN8, HPX, OLFM1, ST6GAL1, CHRDL2, CIDEC, CKB, AVPR2 and others (Additional file 2). Although some of the genes over-expressed in preadipocytes treated with DMIOA relative to nontreated cells are known to have roles in adipogenesis, the majority of them are genes with currently unknown function related to adipogenesis. Although we believe that the study of these genes may provide new insight about adipogenesis, only genes that are known to have direct or indirect roles in adipogenesis and involved in known pathways and molecular functions are discussed here.

Fatty acids have been implicated as potent inducers of adipogenic genes in mammalian [28,29] and chicken $[7,10]$ preadipocytes. Fatty acids, certain prostaglandins, and prostaglandin metabolites are known to function as ligands of PPAR 2 to induce adipogenic differentiation [30]. Treatment of 3 T3-L1 mouse preadipocytes with medium size fatty acids increases the expression of adipocyte specific transcription factors, such as PPAR $2, \mathrm{C} /$ $\mathrm{EBP} \alpha$ and sterol regulatory element binding protein $1 \mathrm{C}$ (SREBP1C), and the major adipocyte marker genes, such as FABP4 and glycerol-3-phosphate dehydrogenase $(\mathrm{GPDH})$ [28]. Rapid increase in PPAR 2 and FABP4 mRNA expression has been reported in preadipocytes isolated from broiler chicken between 9 and $12 \mathrm{hr}$ of OA treatment [7]. In the present study, PPAR 22 and C/ $\mathrm{EBP} \alpha \mathrm{mRNAs}$ were not differentially expressed between cells treated with DMIOA and non-treated cells after 


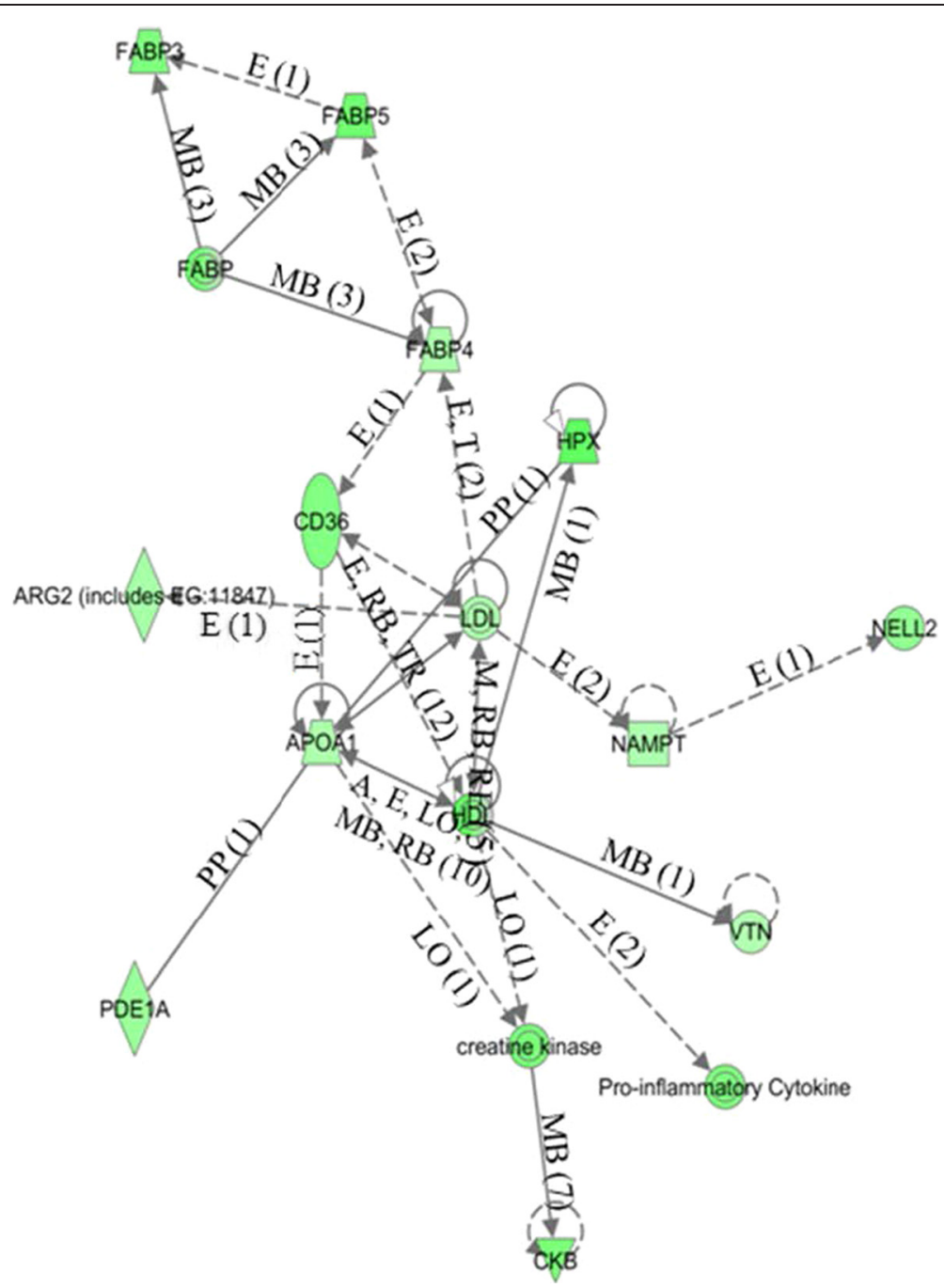

Figure 5 An example of a gene network (lipid metabolism) showing the relationships between molecules over-expressed in cells treated with an adipogenic cocktail (DMIOA) compared with non-treated control cells. The type of the association between two molecules is shown by a letter on the line that connects them. The number in parenthesis next to the letter represents the number of bibliographic references currently available in the Ingenuity Pathways Knowledge Base that support each one of the relationships. Direct or indirect relationships between molecules are indicated by solid or dashed lines connecting them, respectively. $\mathrm{P}=$ phosphorylation, $\mathrm{A}=$ gene activation, $\mathrm{E}=$ increase in expression, $\mathrm{PP}=$ protein-protein interaction, $\mathrm{MB}=$ membership in complex, $\mathrm{LO}=$ localization, $\mathrm{L}=$ proteolysis, $\mathrm{RB}=$ regulation of binding, $\mathrm{TR}=$ Translocation and $\mathrm{T}=$ Transcription. Rhombus, triangular, rectangular, oval, and circular shapes indicate that the molecule belongs to a family of enzymes, phosphatases, growth factors, transmembrane receptors, and other families, respectively.

$96 \mathrm{hr}$ of incubation. These data are consistent with the findings of [7] where higher levels of PPAR 2 and C/ EBPa mRNAs measured between 9-12 hr, and after $24 \mathrm{hr}$ of incubation, respectively, were followed by a sharp decline, suggesting the induction of these genes during the early stages of differentiation as they were not differentially expressed in cells treated with DMIOA after $96 \mathrm{hr}$ incubation in the present study.

Histone deacetylase 9 (HDAC9) was over-expressed in non-treated cells compared with those treated with DMIOA (Additional file 1). Similarly, over-expression of HDAC9 reduces C/EBP $\alpha$ expression and adipogenesis, whereas its knock-out enhances the expression of $\mathrm{C}$ /
EBP $\alpha$ and accelerated adipogenesis in 3 T3-L1 cell lines, demonstrating the anti-adipogenic effect of this gene [31].

Higher expression of one of the key adipocyte specific transcription factors, $C / E B P \beta$, was also measured in cells treated with DMIOA compared with non-treated control cells, and this is consistent with the findings of [7] where its expression level has been progressively increased after $24 \mathrm{hr}$ of incubation, showing an increasing trend with incubation time. However, our data are not fully consistent with the results from 3 T3-L1 mouse preadipocytes study where higher expression of SREBP1C and GPDH activities have been reported [28], explaining the possible 


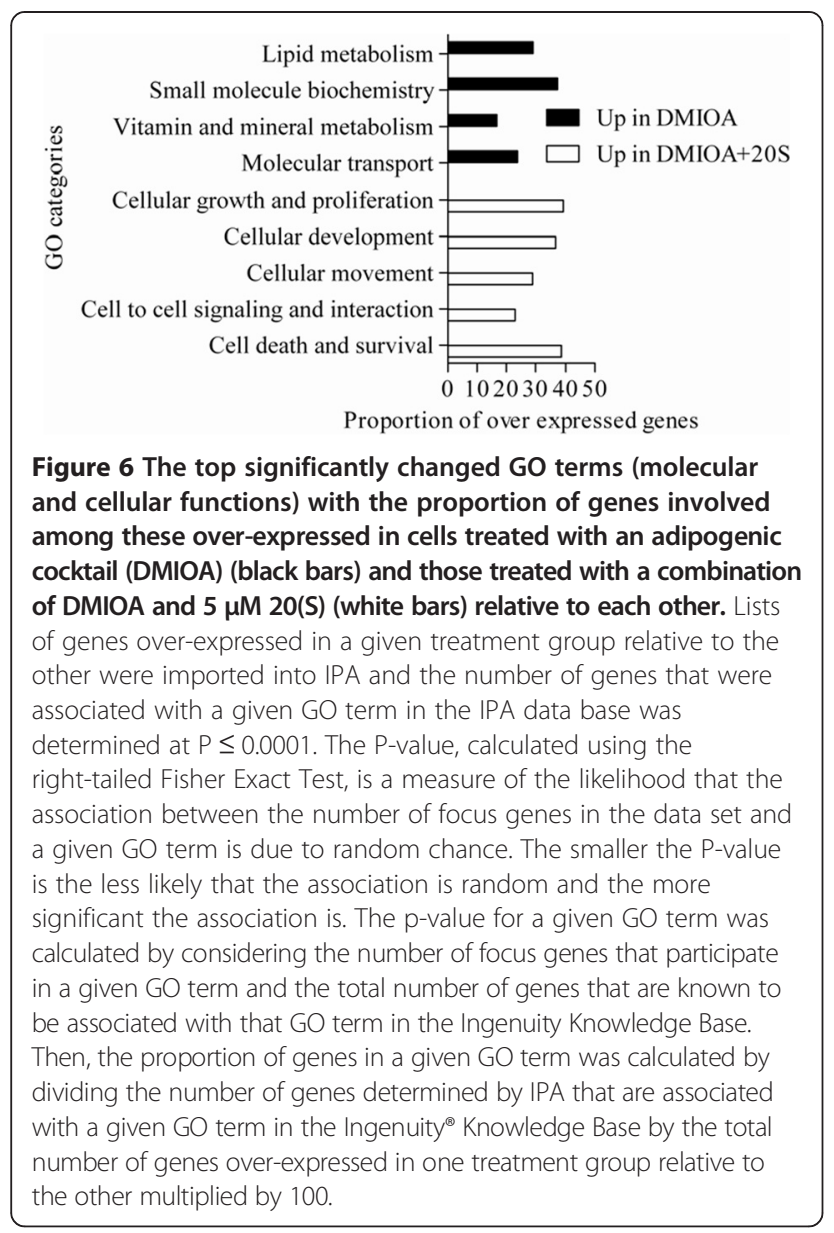

inter-species and incubation time differences in the characteristics of adipocyte differentiation.

The ingenuity pathway analysis indicated that treatment of preadipocytes with DMIOA increased the expression of genes involved in lipid metabolism, including CD36, AGTR2, MAP3K8, APOA1, PTX3, HMOX1 and others (Figure 3). CD36 is a fatty acid transporter molecule that has been implicated to play a functional role in the differentiation of 3 T3-F442A murine preadipocytes into matured adipocytes in in-vitro and in-vivo environments [32], and impaired fatty acid influx and triglyceride synthesis were reported in adipocytes lacking CD36 [33]. Higher expression of CD36 in cells treated with DMIOA compared with non-treated cells in the present study suggests the importance of this transcript in the adipogenesis of hen fat cells.

MAP3K8 is specifically involved in IL-1 $\beta$ and tumor necrosis alpha (TNF- $\alpha$ ) activated MAPK pathway in adipocytes and up-regulated in adipose tissue of obese subjects [34]. Similarly, pentraxin 3 (PTX3) mRNA levels were higher in adipose tissue of genetically obese mice versus control mice [35]. However, whether this higher expression of PTX3 and MAP3K8 in adipose tissue of genetically obese subjects and in DMIOA treated cells is associated with their roles in adipogenesis is not well understood.

Another interesting gene highly expressed in DMIOA treated cells, but not in agreement with the result from mouse study, was heme oxygenase 1 (HMOX1). HMOX1 has been reported to lower the elevated levels of key adipogenic genes, such as PPAR $\gamma$, FABP4, C/

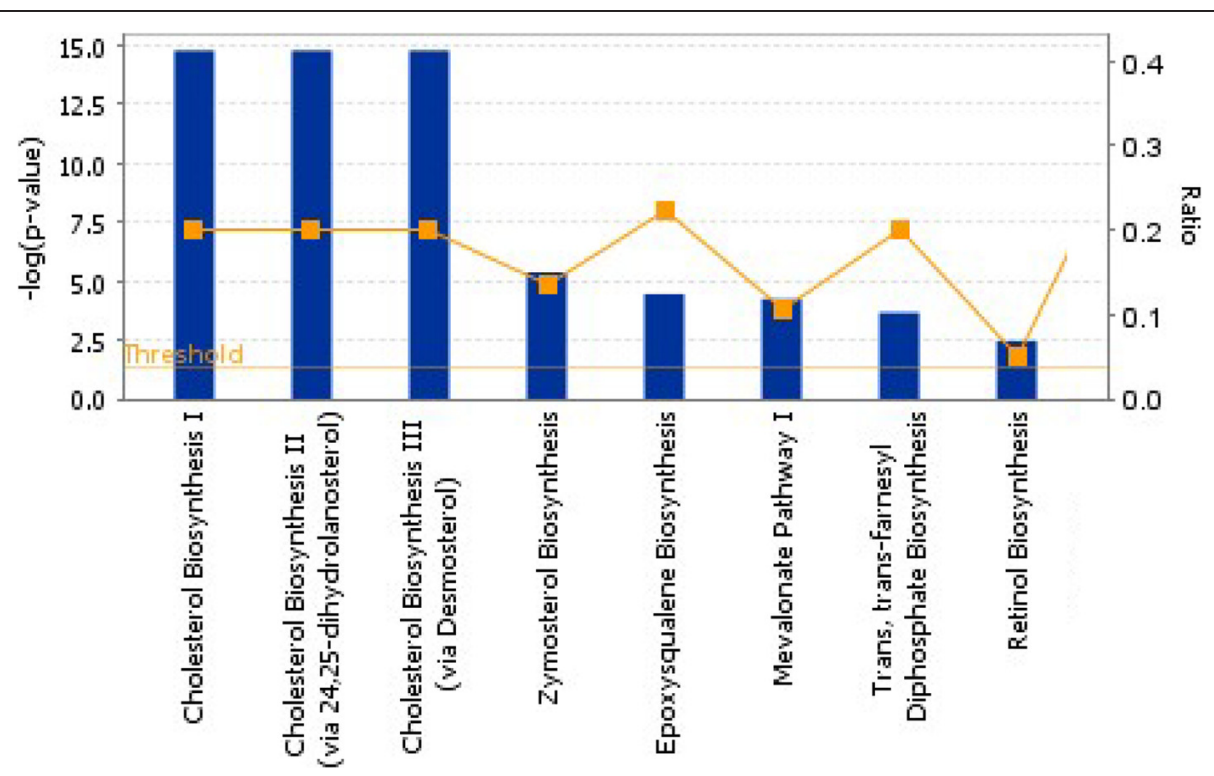

Figure 7 Functional grouping of genes that were over-expressed in cells treated with an adipogenic cocktail (DMIOA) relative to those treated with a DMIOA + $5 \mu \mathrm{M}$ 20(S)-hydroxycholesterol showing the most significant functional groups, with $P$ values, 0.05 . The bars represent the P-value in a logarithmic scale for each functional group. 


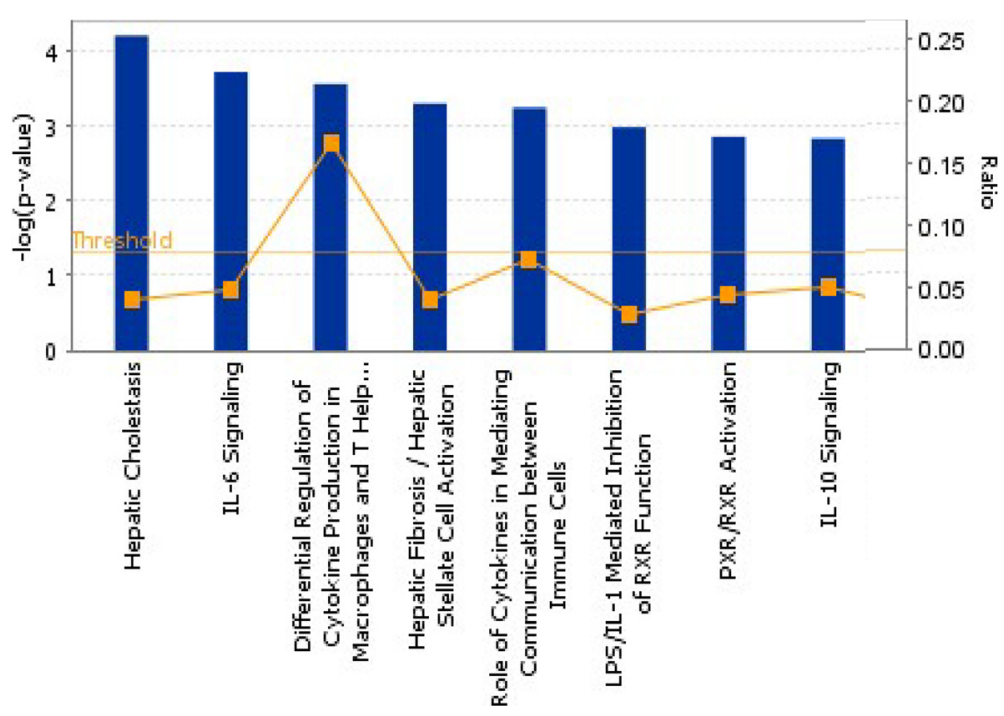

Figure 8 Functional grouping of genes that were over-expressed in preadipocytes treated with an adipogenic cocktail (DMIOA) $+5 \mu M$ 20(S)-hydroxycholesterol relative to those treated with DMIOA alone showing the most significant functional groups, with $\mathrm{P}$ values, 0.05. The bars represent the P-value in a logarithmic scale for each functional group.

EBP $\beta$, and Wnt5B, but increased the expression of antiadipogenic transcription factors, such as sonic hedgehog (Shh), Wnt10B and $\beta$-catenin, in adipocytes isolated from mice fed a high fat diet [36]. However, whether this observed difference is attributed to inter-species differences or high fat diet need to be elucidated.
We found higher transcript expression for arginase 2 (ARG2), hemopexin (HPX), and vitronectin (VTN) in cells treated with DMIOA compared with non-treated cells. These genes are involved in liver $\mathrm{X}$ receptor (LXR)/Retinoid X receptor (RXR) activation pathway, indicating OA possibly induce adipogenesis in hen fat cell

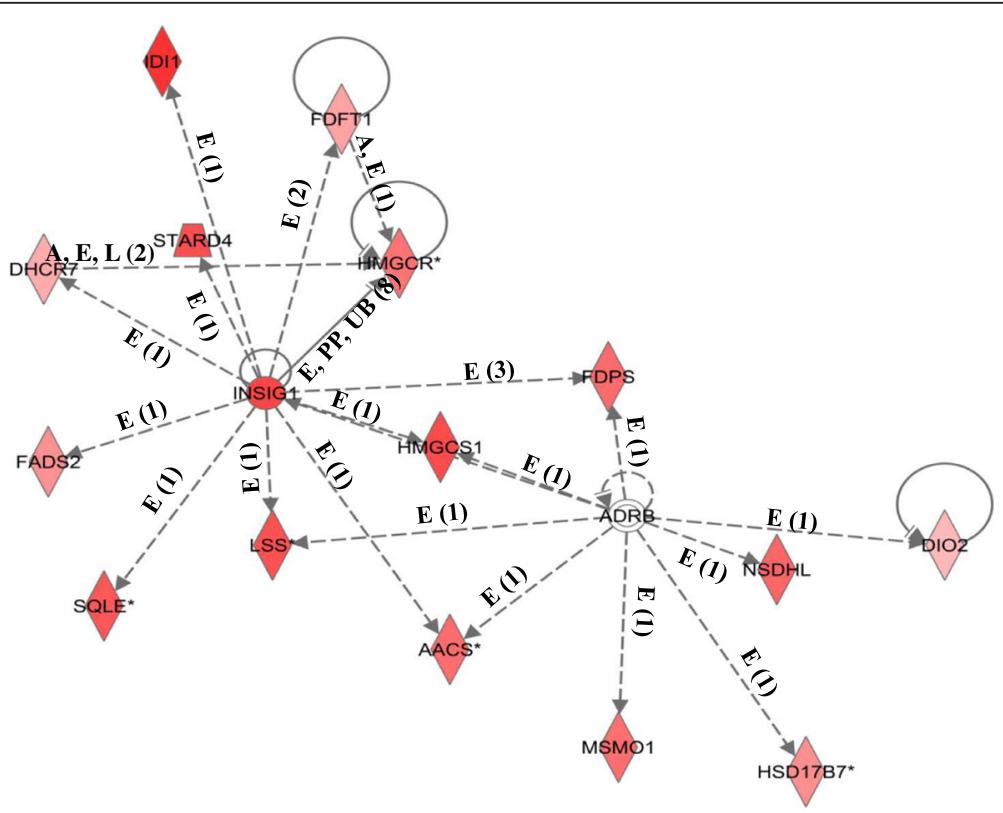

Figure 9 An example of a gene network (lipid metabolism) showing the relationships between molecules over-expressed in cells treated with an adipogenic cocktail (DMIOA) compared with those treated with a combination of DMIOA and $5 \mu \mathrm{M} 20$ (S)-hydroxycholesterol. The type of the association between two molecules is shown as a letter on the line that connects them. The number in parenthesis next to the letter represents the number of bibliographic references currently available in the Ingenuity Pathways Knowledge Base that support each one of the relationships. Direct or indirect relationships between molecules are indicated by solid or dashed lines connecting them, respectively. $A=$ activation, $E=$ increase in expression, $P P=$ protein-protein interaction, $L=$ proteolysis, and $U B=$ ubiquitination. Rhombus shape indicates that the molecule belongs to the family of enzymes, whereas circular shape indicates the molecule belongs to other families. 


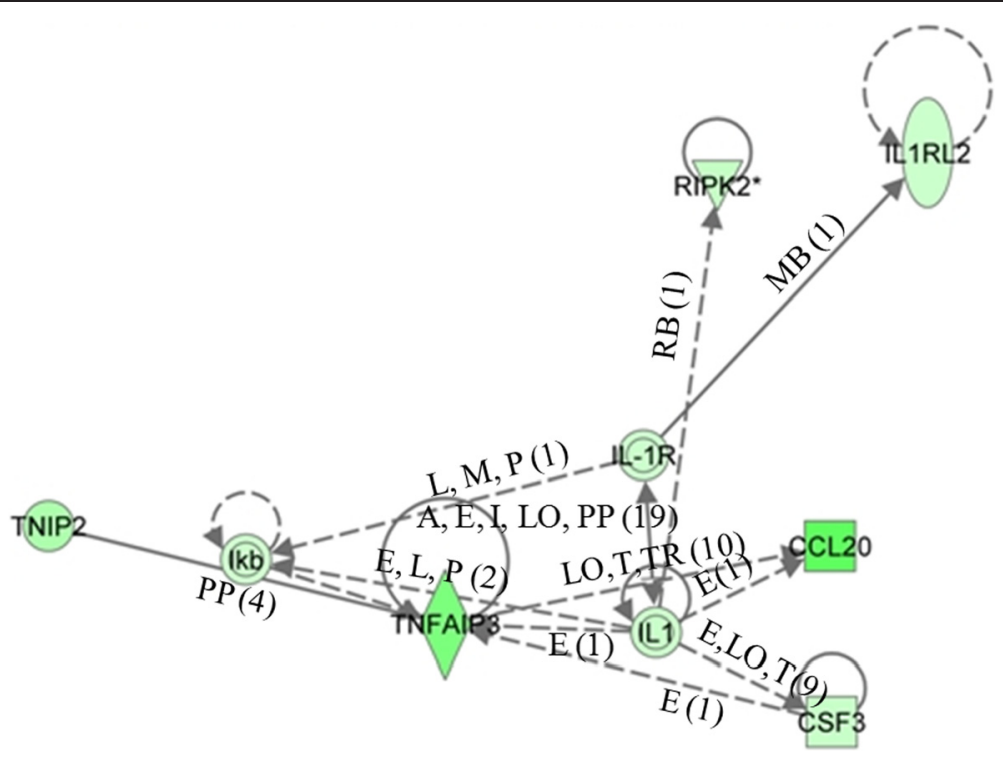

Figure 10 An example of a gene network (cell-to-cell signaling) showing the relationships between molecules over-expressed in cells treated with an adipogenic cocktail (DMIOA) + $5 \mu \mathrm{M}$ 20(S)-hydroxycholesterol compared with those treated with DMIOA alone. The type of the association between two molecules is shown as a letter on the line that connects them. The number in parenthesis next to the letter represents the number of bibliographic references currently available in the Ingenuity Pathways Knowledge Base that support each one of the relationships. Direct or indirect relationships between molecules are indicated by solid or dashed lines connecting them, respectively. $\mathrm{P}=$ phosphorylation, $\mathrm{A}=$ gene activation, $\mathrm{E}=$ increase in expression, $\mathrm{PP}=$ protein-protein interaction, $\mathrm{MB}=$ membership in complex, $\mathrm{LO}=$ localization, $\mathrm{L}=$ proteolysis, $\mathrm{RB}=$ regulation of binding, $T R=$ Translocation and $T=$ Transcription. Triangular, rectangular, oval, and circular shapes indicate that, the molecule represented belongs to the family of phosphatases, growth factors, transmembrane receptors, and others, respectively.

Table 2 Fold change and probability values of qRT-PCR and micro array data

\begin{tabular}{llllll}
\hline Gene name & \multicolumn{2}{l}{ Fold change } & & $P$ value & \\
\cline { 2 - 3 } \cline { 5 - 5 } & RT-PCR & Micro array & & RT-PCR & Micro array \\
\hline CD44 & 8.2 & 5.5 & $P=0.02$ & $P=0.011$ \\
IGFBP7 & 12.1 & 9.1 & $P=0.0002$ & $P=0.046$ \\
VEGFC & 4.1 & 8.5 & $P=0.0001$ & $P=0.027$ \\
MMP1 & 367 & 598.0 & $P=0.001$ & $P=0.001$ \\
APOA1 & 61.0 & 12.2 & $P=0.0009$ & $P=0.021$ \\
STARD4 & 4.0 & 6.2 & & $P=0.0008$ & $P=0.043$ \\
INSIG1 & 6.8 & 6.9 & $P=0.0005$ & $P=0.012$ \\
TGM4 & 4.5 & 4.2 & $P=0.0004$ & $P=0.032$ \\
TNFAIP3 & 4.6 & 9.7 & $P=0.001$ & $P=0.008$ \\
GSTA3 & 1.4 & 5.9 & & $P=0.04$ & $P=0.049$ \\
KLF2 & 6.5 & 3.9 & & $P=0.001$ & $P=0.04$ \\
HAS2 & 0.8 & 6.2 & $P=0.15$ & $P=0.00048$
\end{tabular}

CD44, IGFBP7, and VEGFc were genes over expressed in control cells and MMP1 and APOA1 were genes over expressed in cells treated with DMIOA relative to each other. Similarly, STARD4, INSIG1, and TGM4 were genes over expressed in DMIOA treated cells whereas TNFAIP3, GSTA3, and KLF2 were genes over expressed in cells treated with DMIOA + 20(S) relative to each other. through activation of LXR/RXR pathways. The role/s of LXR/RXR pathway appears to vary from cells to cells and from species to species. For instance, suppression of LXR $\alpha$ markedly reduces the expression of lipogenic (FAS and SREBP1C) and adipogenic transcription factors (PPAR 2 and FABP4) and adipogenesis in 3 T3-L1 mouse cells [37]. Similarly, suppression of LXR negatively regulates adipogenesis in C57BL/6 mouse cells [38] suggesting that LXR $\alpha$ can be an important transcription factor mediating adipocyte differentiation as well as adipogenic gene expression. On the contrary, knock-down of LXR $\alpha$ and LXR $\beta$ in mouse M2 bone marrow stromal cells significantly reduced the expression of key osteogenic genes, BSP, OCN, and HES1, showing the critical role of LXRs in regulating mouse MSC osteogenic differentiation [39] that has a reciprocal interaction with adipogenic differentiation. In another study, activation of LXR $\alpha$ resulted in lipolysis of human 3 T3-L1 cells [40] showing inter-species differences.

We also found higher expression of genes involved in IL-10 signaling, such as IL-1R1, IL-1RL1, and IL-1RL2, and these involved in lipopolysaccharide (LPS)/IL-1 mediated inhibition of RXR including FABP3, 4, 5, and SOD3 pathways in cells treated with DMIOA compared with non-treated cells. Interleukin 10 (IL-10) is a potent anti-inflammatory and immunosuppressive cytokine mediating its pleiotropic effects on different immune cells 
through the trans-membrane heterotetrameric complex composed of IL-10R1 and IL-10R2 chains [41]. Adipose tissue is a rich source of anti-inflammatory factors such as IL-10 [42,43], and adipose size is an important determinant of adipokine secretion [44]. However, data showing the role of IL-10 signaling pathway itself in adipogenesis is not available and hence molecular mechanisms of the IL-10 and other signaling pathways in adipogenesis by DMIOA treatment is to be elucidated.

Fatty acid binding proteins (FABP3, 4 and 5) play important roles in adipogenic differentiation of fat cells in various species $[7,10,45]$. Consistent with this, DMIOA treatment increased the expression of molecules involved in the lipid metabolism gene network such FABP3, 4 and 5, APOA1, LDL, and others (Figure 5). Although both FABP4 and FABP5 are expressed in adipose tissue, only the regulatory role of FABP4 in adipogenesis has been widely investigated. Increased expression of FABP4 has been reported in DMIOA-induced adipogenic differentiation of preadipocytes isolated from chicken $[7,10]$. A coordinated expression of FABP3, FABP4 and FABP5 together with that of PPAR $\alpha$, PPAR $\gamma 1$ and PPAR 2 is critical for metabolic regulation of adipogenesis in porcine preadipocytes [45]. Contrastingly, FABPs are not differentially expressed between fat and lean lines of 7-wk old broiler chicken [25].

It has been reported that basic fibroblast growth factor enhances PPAR 2 ligand-induced adipogenesis in rat MSC [46], and FGFR1 is a key regulator of adipogenesis in human $[47,48]$. In the present study, we also found higher expression of FGFR1 in cells treated with DMIOA compared to non-treated cells showing the involvement of this transcript in chicken adipogenesis.

\section{The effect of 20(S) hydroxycholesterol on adipogenesis and expression of adipogenic genes}

Studies have indicated that specific oxysterols are capable of inhibiting the expression of several adipogenic transcription factors and adipogenesis in mammalian cells $[15,16,18,19]$. Here, we report for the first time that 20(S) inhibits the adipogenic differentiation of preadipocytes in laying hen.

It has been reported that treatment of murine M210B4 MSC with 20(S) completely inhibits troglitazoneinduced PPAR 2 expression and adipocyte formation through the activation of the Hh signaling pathway [15]. Moreover, 20(S) induces the expression of notch target genes such as HEY 1/2 and HES1 in M2-10B4 pluripotent mouse stromal cells [39]. Osteogenic oxysterols have also been reported to inhibit adipogenesis and the expression of LPL and FABP4 in murine pluripotent MSC [16]. In this study, treatment of laying hen preadipocytes with $20(\mathrm{~S})$ inhibited the mRNA expression of adipogenic differentiation marker (FABP4) and fatty acid transporter molecule (CD36) (Additional files 5 and 6). However, PPAR $\gamma 2$, LPL, C/EBP $\beta, \mathrm{C} / \mathrm{EBP} \alpha$ and other adipogenic transcription factors were not differentially expressed between DMIOA and DMIOA + 20(S) treated cells. This could be attributed to the fact that these key adipogenic genes are induced during the earlier stages of adipogenic differentiation and hence their mRNA changes were not detected at the later stages, where cells already differentiated. Although 20(S) inhibits PPAR 22 expression and adipogenesis through the activation of the Hh signaling pathway in mouse MSC [15], Hh signaling pathway was not activated by 20 (S) treatment in the present study explaining inter-species differences. This suggests that the anti-adipogenic effects of 20(S) may not be mediated through Hh signaling pathway in chicken. Additionally, the network analysis of genes over-expressed in DMIOA treated cells relative to DMIOA $+20(\mathrm{~S})$ showed large proportion of molecules involved in lipid metabolism indicating the potential of 20 (S) to reduce excessive fat accumulation (Figure 9). We found over-expression of genes such as INSIG1, STARD4, DHCR7 and 24 and others in cells treated with DMIOA compared with those treated with DMIOA +20 (S). Studies have indicated that INSIG1 is expressed in parallel with FABP4 in differentiating 3 T3-L1 mouse preadipocytes [49], and STARD4 mediates cholesterol transport during cholesterol homeostasis [50]. Genes involved in cell-to-cell signaling networks such as IL1, IL1R, IL1RL2, CCL20, TNFAIP3, IKB, TNIP2, CSF3 and RIPK2 were also over-expressed in preadipocytes treated with DMIOA + 20(S) compared with those treated with DMIOA (Figure 10). Interleukin 1 (IL-1) plays an important role in bone metabolism through activation of receptor activator of NF- $\mathrm{kB}$ signaling pathway in mouse models [51], and IL-1R is an important mediator involved in many cytokine induced immune and inflammatory responses [52]. Additionally, it has been shown that cytokines such as IL-1 and tumour-necrosis factoralpha (TNFA) inhibit adipogenesis in bone marrow [53]. Hence, over-expression of IL-1, its receptor mRNA (IL-1R) and tumor necrosis alpha induced protein 3 (TNFAIP3) in cells treated with DMIOA $+20($ S) relative to those treated with DMIOA indicates that 20 (S) potentially inhibits chicken adipogenesis through induction of anti-adipogenic cytokines. However, the role/s of cytokines on adipogenesis and adipogenic gene expression in hen preadipocytes need further elucidation.

Genes over-expressed in preadipocytes treated with DMIOA $+20($ S) relative to those treated with DMIOA alone include KLF2 and 6, early growth response 1 (EGR1), CD44, and CCK. The Kruppel-like factor (KLF2) has been implicated to reduce adipogenesis by inhibiting PPAR $\gamma$ expression in 3 T3-L1 cells [54]. Similarly, ectopic expression of EGR1 has been reported to 
inhibit adipocyte differentiation in murine 3 T3-L1 preadipocytes [55]. Consistent with these findings, KLF2 and EGR1 were over-expressed in cells treated with DMIOA +20 (S) relative to cells treated with DMIOA where adipogenesis was markedly reduced. Interestingly, these genes were over-expressed in control cells relative to those treated with DMIOA, indicating that KLF2 and EGR1 could potentially involve in the inhibition of adipogenesis in chicken fat cells.

Studies have shown that increased CD44 expression is accompanied with obesity-induced hepatic steatosis and white adipose tissue-associated inflammation in human and mouse, suggesting CD44 might play a critical role in regulating obesity and associated pathologies [56,57]. On the other hand, because it is a multifunctional cell membrane protein, CD44 can act as a receptor for hyaluronan (HA) and osteopontin [58,59]. In line with this, exogenous HA application increased calcium deposition in pig bone marrow stromal cells [59], and osteopontin expression was enhanced during bone formation in mouse [60], indicating the possible involvement of CD44 in bone development. Considering the potential of 20(S) to induce the expression of genes associated with osteogenesis in M2-10B4 bone marrow stromal cells [15], increased expression of CD44 in cells treated with DMIOA $+20(S)$ in the present study may explain the pro-oesteogenic property of 20(S) [15] which could negatively modulate key adipogenic regulators by enhancing the expression of CD44. The expression of CCK was also increased in hen preadipocytes treated with DMIOA + 20(S) compared with those treated with DMIOA alone. Cholecystokinin (CCK) is involved in regulating the metabolic rate and is important for lipid absorption and control of body weight in mice placed on a high-fat diet [61], showing its anti-adipogenic effect in vivo. However, the potential of this gene as an antiadipogenic factor in hen adipocytes needs further investigation.

In summary, treatment of hen preadipocytes with DMIOA highly induced the expression of genes involved in lipid metabolism relative to non-treated cells. On the other hand, preadipocytes treated with a combination of DMIOA and 20(S) inhibited expression of key adipogenic transcripts and adipogenesis as compared with cells treated with DMIOA alone. Moreover, 20(S) increased the expression of many key genes previously reported to enhance osteogenesis which has a reciprocal relationship to adipogenesis.

\section{Conclusions}

This study generated important gene expression data that would enhance our understanding of the biology of adipocytes. The study demonstrated that 20 (S) is capable of reducing DMIOA-induced adipogenesis and identified potential adipogenic and anti-adipogenic regulators in hen preadipocytes that require further investigation.

\section{Supporting data}

All supporting data for this study are included as additional files.

\section{Additional files}

\begin{abstract}
Additional file 1: List of genes over-expressed (Fold change $\geq 2$ ) in control cells relative to cells treated with an adipogenic cocktail (DMIOA) for $96 \mathrm{hr}$.

Additional file 2: List of genes over-expressed (Fold change $\geq 2$ ) in cells treated with an adipogenic cocktail (DMIOA) for $96 \mathrm{hr}$.

Additional file 3: Hierarchical clustering and heat map of all genes differentially expressed between control cells and cells treated with an adipogenic cocktail (DMIOA) for $\mathbf{9 6} \mathbf{~ h r}$. Numbers 1 and 2 at the top of the heat map indicate the three biological replications representing control cells and cells treated with DMIOA, respectively. The fold change increases from green to red.
\end{abstract}

Additional file 4: Hierarchical clustering and heat map of the top 20 genes differentially expressed between control cells and cells treated with an adipogenic cocktail (DMIOA for $96 \mathrm{hr}$. Numbers 1 and 2 at the top of the heat map indicate the three biological replications representing control cells and cells treated with DMIOA, respectively. The fold change increases from green to red.

Additional file 5: List of genes over-expressed (Fold change $\geq 2$ ) in cells treated with an adipogenic cocktail (DMIOA) for $96 \mathrm{hr}$.

Additional file 6: List of genes over-expressed (Fold change $\geq 2$ ) in cells treated with an adipogenic cocktail (DMIOA) for $96 \mathrm{hr}$.

Additional file 7: Hierarchical clustering and heat map of all genes differentially expressed between cells treated with an adipogenic cocktail (DMIOA) for $\mathbf{9 6}$ hr. Numbers 1 and 2 at the top of the heat map indicate the three biological replications representing cells treated with DMIOA and DMIOA + 20(S), respectively. The fold change increases from green to red.

Additional file 8: Hierarchical clustering and heat map of the top 20 genes differentially expressed between cells treated with an adipogenic cocktail (DMIOA) for 96 hr. Numbers 1 and 2 at the top of the heat map indicate the three biological replications representing cells treated with $\mathrm{DMIOA}$ and $\mathrm{DMIOA}+20(\mathrm{~S})$, respectively. The fold change increases from green to red.

\section{Abbreviations}

DMIOA: Dexamethasone + 3-isobutyl-1-methylxanthine + insulin + 300 oleic acid; OA: Oleic acid; C/EBP $\beta$ : The core enhancer binding protein beta; C/EBPa: The core enhancer binding protein alpha; GSK3 $\beta$ : Glycogen synthase kinase -3- beta; MAPK: Mito gene activated protein kinase; MSC: Mesenchymal stem cell; PKA: Protein kinase A; PKC: Protein kinase C; Hh: Hedgehog; Min: Minutes; Hr: Hour; DMEM: Dulbecco's Eagle's Medium; RPM: Revolution per minute; FBS: Fetal bovine serum; GCRMA: Guanine cytosine robust multichip average; qRT-PCR: Quantitative real-time reverse transcriptase polymerase chain reaction; NCBI: National Centre for Biological Information

Competing interests

The authors declare that they have no competing interests.

\section{Authors' contributions}

AR carried out the experiment, analyzed the data, prepared manuscript and contributed to experimental design. WKK was in charge of the overall project, designed the study, interpreted the data, and edited the manuscript. All authors read and approved the final manuscript. 


\section{Acknowledgments}

This study was supported by Natural Science and Engineering Research Council (NSERC-discovery), Cooperative Research Program for Agriculture Science \& Technology Development (Project No. PJ009422), Rural Development Administration, Republic of Korea, and University of Georgia starup grant.

Received: 18 September 2014 Accepted: 12 January 2015 Published online: 18 February 2015

\section{References}

1. Cornelius P, MacDougald OA, Lane MD. Regulation of adipocyte development. Ann Rev nutri. 1994;14:99-129.

2. Soukas A, Socci ND, Saatkamp BD, Novelli S, Friedman JM. Distinct transcriptional profiles of adipogenesis in vivo and in vitro. J Biol Chem. 2001;76:34176-4

3. Tang QQ, Lane MD. Adipogenesis: from stem cell to adipocyte. Annu Rev Biochem. 2012;81:715-36.

4. Otto TC, Lane MD. Adipose development: from stem cell to adipocyte. Crit Rev Biochem Mol Biol. 2005;40:229-42

5. MacDougald OA, Mandrup S. Adipogenesis: forces that tip the scales. Trends Endocrinol Metab. 2002;13:5-11.

6. Tang QQ, Grønborg M, Huang H, Kim JW, Otto TC, Pandey A, et al. Sequential phosphorylation of CCAAT enhancer-binding protein by MAPK and glycogen synthase kinase 3 is required for adipogenesis. Proc Natl Acad Sci U S A. 2005;102:9766-71.

7. Matsubara $Y$, Sato $K$, Ishii $H$, Akiba $Y$. Changes in mRNA expression of regulatory factors involved in adipocyte differentiation during fatty acid induced adipogenesis in chicken. Comp Biochem and Physiol. 2005;141:108-15. Part A.

8. Rosen D, Hsu CH, Wang X, Sakai S, Freeman MW, Gonzalez FJ, et al. C/EBP induces adipogenesis through PPAR a unified pathway. Genes Dev. 2002:16:22-6.

9. Fernyhough ME, Okine E, Hausman G, Vierck JL, Dodson MV. PPARy and GLUT-4 expression as developmental regulators/markers for preadipocyte differentiation into an adipocyte. Domest Anim Endocrinol. 2007;33:367-78.

10. Regassa A, Kim WK. The effects of oleic acid and chicken serum on the expression of adipogenic transcription factors and adipogenic differentiation in hen preadipocytes. Cell Biol Int. 2013;37:961-71.

11. Venkateswaran A, Laffitte BA, Joseph SB, Mak PA, Wilpitz DC, Edwards PA, et al. Control of cellular cholesterol efflux by the nuclear oxysterol receptor LXRa. Proc Natl Acad Sci U S A. 2000;22:12097-102.

12. Kolsch H, Lutjohann D, Tulke A, Bjorkhem I, Rao ML. The neurotoxic effect of 24-hydroxycholesterol on SH-SY5Y human neuroblastoma cells. Brain Res. 1999;818:171-5

13. Hanley K, Ng DC, He SS, Lau P, Min K, Elias PM, et al. Oxysterols induce differentiation in human keratinocytes and increase Ap-1 dependent involucrin transcription. J Investig Dermatol Symp Proc. 2000;114:545-53.

14. Panini SR, Sinensky MS. Mechanisms of oxysterol induced apoptosis. Curr Opin Lipidol. 2001;12:529-33.

15. Kim WK, Meliton V, Amantea CM, Hahn TJ, Parhami F. 20(S)hydroxycholesterol inhibits PPAR gamma expression and adipogenic differentiation of bone marrow stromal cells through a hedgehogdependent mechanism. J Bone Miner Res. 2007;22:1711-9.

16. Kha HT, Basseri B, Shouhed D, Richardson J, Tetradis S, Hahn TJ, et al. Oxysterols regulate differentiation of mesenchymal stem cells: Pro-bone and anti-fat. J Bone Miner Res. 2004;19:830-40.

17. Richardson JA, Amentea CM, Kianmahd B, Tetradis S, Lieberman JR, Hahn TJ, et al. Oxysterol-induced osteoblastic differentiation of pluripotent mesenchymal cells is mediated through a PKC- and PKA-dependent pathway. J Cell Biochem. 2007;100:1131-45.

18. Johnson JS, Meliton V, Kim WK, Lee KB, Wang JC, Nguyen K, et al. Novel oxysterols have pro-osteogenic and anti-adipogenic effects in vitro and induce spinal fusion in vivo. J Cell Biochem. 2011;12:1673-84

19. Luchetti F, Canonico B, Cesarini E, Tortoioli C, Arcangeletti M, Galli L, Iuliano L, Murdolo G, Galli F, Papa S. New role of oxysterols as regulators of adipogenic differentation in adipose-derived mesenchymal stem cells. Ital J Anat Embryol. 2011;116:1 (Supplement).

20. 26. Protocol for Oil red $\mathrm{O}$ staining for in vitro adipogenesis [http://bio.lonza. com/uploads/tx_mwaxmarketingmaterial/Lonza_ManualsProductInstructions_ Oil_Red_O_Stain_for_In_Vitro_Adipogenesis.pdf].
21. Blazejczyk M, Miron M, Nadon R. FlexArray: a statistical data analysis software for gene expression microarrays. Genome Quebec: Montreal, Canada; 2007

22. Irizarry RA, Bolstad BM, Collin F, Cope LM, Hobbs B, Speed TP. Summaries of Affymetrix GeneChip probe level data. Nucleic Acids Res. 2003;31:e15.

23. Ingenuity Pathway Analysis Systems [http://www.ingenuity.com]

24. SAS (Statistical Analysis System). Version 9.4. SAS Institute Inc., Cary, NC, USA; 2013.

25. Wang H, Li H, Wang Q, Zhang X, Wang S, Wang Y, et al. Profiling of chicken adipose tissue gene expression by genome array. BMC Genomics. 2007;8:193.

26. Resnyk CW, Carré W, Wang X, Porter T, Simon J, Le Bihan-Duval E, et al. Transcriptional analysis of abdominal fat in genetically fat and lean chickens reveals adipokines, lipogenic genes and a link between hemostasis and leanness. BMC Genomics. 2013;14:557.

27. Cui H, Liu R, Zhao G, Zheng M, Chen J, Wen J. Identification of differentially expressed genes and pathways for intramuscular fat deposition in pectoralis major tissues of fast-and slow-growing chickens. BMC Genomics. 2012;13:213.

28. Yanga JY, Della-Feraa MA, Rayalama S, Parka HJ, Ambatia S, Hausmana DB, et al. Regulation of adipogenesis by medium-chain fatty acids in the absence of hormonal cocktail. J Nutri Biochem. 2009;20:537-43.

29. Kobayashi T, Fujimori K. Very long-chain-fatty acids enhance adipogenesis through co regulation of Elovl3 and PPARy2 in 3 T3-L1 cells. Am J Physiol Endocrinol Metab. 2012;302:E1461-71

30. Kota BP, Huang TH, Roufogalis BD. An overview on biological mechanisms of PPARs. Pharmacol Res. 2005;51:85-94.

31. Chatterjee TK, Idelman G, Blanco V, Blomkalns AL, Piegore MG, Weintraub DS, et al. Histone Deacetylase 9 is a negative regulator of adipogenic differentiation. J Biol Chem. 2011;286:27836-47.

32. Christiaens V, Van Hul M, Lijnen HR. CD36 promotes adipocyte differentiation and adipogenesis. Biochim Biophys Acta. 2012;1820:949-56.

33. Coburn $C T$, Knapp FF, Febbraio M, Beets AL, Silverstein RL, Abumrad NA Defective uptake and utilization of long chain fatty acids in muscle and adipose tissues of CD36 knockout mice. J Biol Chem. 2000;275:32523-9.

34. Jager J, Grémeaux T, Gonzalez T, Bonnafous S, Debard C, Laville M, et al. Tpl2 kinase Is upregulated in adipose tissue in obesity and may mediate interleukin-1 $\beta$ and tumor necrosis factor- $a$ effects on extracellular signalregulated kinase activation and lipolysis. Diabetes. 2010:59:61-70.

35. Abderrahim-Ferkoune A, Bezy O, Chiellini C, Maffei M, Grimaldi P, Bonino F, et al. Characterization of the long pentraxin PTX3 as a TNFa-induced secreted protein of adipose cells. J Lipid Res. 2003;44:994-1000.

36. Cao J, Peterson SJ, Sodhi K, Vanella L, Barbagallo I, Rodella LF, et al. Heme oxygenase gene targeting adipocytes attenuates adiposity and vascular dysfunction in mice fed a high-fat diet. Hypertens. 2012;60:467-75.

37. Seo JB, Moon HM, Kim WS, Lee YS, Jeong HW, Yoo EJ, et al. Activated liver $X$ receptors stimulate adipocyte differentiation through induction of peroxisome proliferator-activated receptor $\gamma$ expression. Mol Cell Biol. 2004;24:3430-44

38. Li X, Shridas P, Forrest K, Bailey W, Webb RN. Group X secretory phospholipase A2 negatively regulates adipogenesis in murine models. The FASEB J. 2010:24:4313-24.

39. Kim WK, Meliton V, Tetradis S, Weinmaster G, Hahn TJ, Carlson M, et al. Osteogenic oxysterol, 20(S)-hydroxycholesterol, induces notch target gene expression in bone marrow stromal cells. J Bone Miner Res. 2010;25:782-95.

40. Stenson BM, Rydén M, Venteclef N, Dahlman I, Pettersson AM, Mairal A, et al. Liver $X$ receptor $(L X R)$ regulates human adipocyte lipolysis. J Biol Chem. 2011;286:370-9.

41. Moore KW, de Waal Malefyt R, Coffman RL, O'Garra A. Interleukin-10 and the interleukin-10 receptor. Annu Rev Immunol. 2001;19:683-765.

42. Gotoh K, Inoue M, Masaki T, Chiba S, Shimasaki T, Ando H, et al. A nove anti-inflammatory role for spleen-derived interleukin-10 in obesity-induced inflammation in white adipose tissue and liver. Diabetes. 2012;61:1994-2003.

43. Juge-Aubry CE, Somm E, Pernin A, Alizadeh N, Giusti V, Dayer JM, et al. Adipose tissue is a regulated source of interleukin-10. Cytokine. 2005;29:270-4

44. Skurk $\mathrm{T}$, Alberti-Huber $\mathrm{C}$, Herder $\mathrm{C}$, Hauner $\mathrm{H}$. Relationship between adipocyte size and adipokine expression and secretion. J Clin Endocrinol Metab. 2007:92:1023-33.

45. Samulin J, Berget I, Lien S, Sundvold H. Differential gene expression of fatty acid binding proteins during porcine adipogenesis. Comp Biochem Physio B Biochem Mol Biol. 2008;151:147-52. 
46. Neubauer M, Fischbach C, Bauer-Kreisel P, Lieb E, Hacker M, Tessmar J, et al. Basic fibroblast growth factor enhances PPARY2 ligand-induced adipogenesis of mesenchymal stem cells. FEBS Lett. 2004;577:277-83.

47. Widberg $\mathrm{CH}$, Newell FS, Bachmann AW, Ramnoruth SN, Spelta MC Whitehead JP, et al. Fibroblast growth factor receptor 1 is a key regulator of early adipogenic events in human preadipocytes. Am J Physiol Endocrinol Metab. 2009;296:E121-31.

48. Hutley L, Shurety W, Newell F, McGeary R, Pelton N, Grant J. Fibroblast growth factor a Key regulator of human adipogenesis. Diabetes. 2004;53:3095-106

49. Li J, Takaishi K, Cook W, McCorkle SK, Unger RH. INSIG-1 "brakes" lipogenesis in adipocytes and inhibits differentiation of preadipocytes. Proc Natl Acad Sci U S A. 2003;100:9476-81.

50. Mesmin B, Pipalia NH, Lund FW, Ramlall TF, Sokolov A, Eliezer D, et al. STARD4 abundance regulates sterol transport and sensing. Mol Biol Cell. 2011;22:4004-15

51. Lee YM, Fujikado N, Manaka H, Yasuda H, Iwakura Y. IL-1 plays an important role in the bone metabolism under physiological conditions. Int Immunol. 2010;22:805-16.

52. Thomas C, Bazan JF, Garcia KC. Structure of the activating IL-1 receptor signaling complex. Nat Struct Mol Biol. 2012;19:455-7.

53. Suzawa I, Takada I, Yanagisawa J, Ohtake F, Ogawa S, Yamauchi T, et al. Cytokines suppress adipogenesis and PPAR- $\gamma$ function through the TAK1/ TAB1/NIK cascade. Nature Cell Biol. 2003:5:224-30.

54. Banerjee SS, Feinberg MW, Watanabe M, Gray S, Haspel RL, Denkinger DJ, et al. The krüppel-like factor inhibits peroxisome proliferator-activated receptor- $\gamma$ expression and adipogenesis. J Biol Chem. 2003;278:2581-4.

55. Boyle KB, Hadaschik D, Virtue S, Cawthorn WP, Ridley SH, O'Rahilly S, et al. The transcription factors Egr1 and Egr2 have opposing influences on adipocyte differentiation. Cell Death Differ. 2009;16:782-9.

56. Kodama K, Horikoshi M, Toda K, Yamada S, Hara K, Irie J, et al. Expressionbased genome-wide association study links the receptor CD44 in adipose tissue with type 2 diabetes. Proc Natl Acad Sci U S A. 2012. doi:10.1073/ pnas.1114513109.

57. Johnson P, Ruffell B. CD44 and its role in inflammation and inflammatory diseases. Inflamm Allergy Drug Targets. 2009:8:208-20.

58. Toole BP. Hyaluronan-CD44 interactions in cancer: paradoxes and possibilities. Clin Cancer Res. 2009;15:7462-8.

59. Zou L, Zou X, Chen L, Li H, Mygind T, Kassem M, et al. Effect of hyaluronan on osteogenic differentiation of porcine bone marrow stromal cells in vitro. J Orthop Res. 2008:26:713-20.

60. Morinobu M, Ishijima M, Rittling SR, Tsuji K, Yamamoto H, Nifuji A, et al. Osteopontin expression in osteoblasts and osteocytes during bone formation under mechanical stress in the calvarial suture in vivo. J Bone Miner Res. 2003;18:1706-15

61. LO CM, King A, Samuelson LC, Kindel TL, Rider T, Jandacek RJ, et al. Cholecystokinin knockout mice are resistant to high-fat diet-induced obesity. Gastroenterol. 2010;138:1997-2005.

\section{Submit your next manuscript to BioMed Central and take full advantage of:}

- Convenient online submission

- Thorough peer review

- No space constraints or color figure charges

- Immediate publication on acceptance

- Inclusion in PubMed, CAS, Scopus and Google Scholar

- Research which is freely available for redistribution 